\title{
Urban Development Plan Using Open Source Geospatial Technology - A Case Study of Ahmedabad.
}

\author{
D.Rawal ${ }^{1}$, V.Gupta ${ }^{1}$ A. Vyas $^{2}$ \\ vishal.gupta@ctu.org.in \\ ${ }^{1}$ Calorx Teachers' University, Ahmedabad - rawalnet@yahoo.com, \\ ${ }^{1}$ Dept. of Geography, Calorx Teacher University, Ahmedabad \\ 2 Center for Applied Geomatics, CEPT University, Ahmedabad
}

Commission IV, WG IV/4

KEY WORDS: Urban Growth, GDCR, DCR, Land Use and Land Management

\begin{abstract}
:
Approximately by the year $2030,40 \%$ of population of a country will be urbanised. This indicates a tremendous opportunity in sector of constructing units for fulfilling Residential as well as commercial requirements. Construction activity takes place on land, it must be noted that land solely is not responsible. There are various regulations which affect the extent to which construction/land utilization can takes place. The two most significant factors which affects utilization of land are Zoning and Development Control regulation. Zoning will broadly determine land use while DCR varies depending on size of plot, height achieved by a construction activity and purpose for which it is being used. Development plan determines zone in which a land will be lying (i.e., from Macroscopic point of view), it determines the activity permitted and largely the FSI allotted for each zone. While General Development Control Regulation (GDCR) gives detailed structure regarding permitted activities for the land as well as minimum area of construction depending on its typology. In addition to its height as well as margin depends on factors like Road length and surrounding structure. Using the buildable area of a plot, the total built-up area in a city can be calculated based on the FSI provided in various zones that helps in providing sufficient infrastructure for the future It also gives an estimate on how much land needs to be opened up in future to accommodate the future population Study focuses on developing a Geospatial solution which can incorporate all these factors when a particular construction activity needs to be conducted. By obtaining buildable are one can forecast various infrastructural elements which needs to be implant along with various emergency provision of Fire Safety and Identify the Roof tops to fixed up the Solar penal, develop a public utility, other such.
\end{abstract}

\section{INTRODUCITON}

\subsection{Patterns of the Urbanizations in India:}

The growth of the urban population in India has been extremely rapid during the course of last century. While the total population of India has grown from 361 million in 1961 to 1210 million in 2011 .The urban populations has increased from 62 million to 377 million in the same period. The percentage share of urban population has gone up from $17.3 \%$ in 1951 to $31.16 \%$ in 2011 . The numbers of urban settlements too have gone up from 2845 in 1951 to 7933 in 2011. The share of Class- 1 cities (with population of one lakh and above) in the total urban population has increased from $44 \%$ to $70 \%$ during the above period. The concentration of population within the 'million plus cities has been notably putting. Their number has increased from 5 in 1951 and 53 in 2011. These 53 cities together had a population of 160.7 million in 2011, accounting for $42.6 \%$ of India's urban population. The total population in India is expected to be 1350 million by 2021 . According to United Nations the total population of India is estimated to be 1440 million by 2025 and 1700 million by 2050 respectively. The total urban population of India is projected to be about $40 \%$ of country's total population by 2021 with the number of class- 1 cities expected to rise to about 800 by 2021 . The number of million plus cities is expected to be around 60 by 2021 . In view of the rapidly growing population, pressure on the urban transport system is bound to increase much more in the coming years.

\subsection{The Challenges in Urbanization and its Planning}

India's cities and towns polluted, unliveable, inefficient and most importantly its makes city us sustainable because lack of involvement of public leading to non-implicated plans. Cities and cities are crucial to the economic well-being of Asian nation. For this, it is imperative that its cities and towns are transformed and pressures of new growth are dealt with so that they are more it's a difficult challenge that India faces in managing the rapid growth of cities with the current rate of urbanization. It is ranked second in terms of its population in the world, with a total population of 1.311 billion and, of this, $32.4 \%$ live in its 7,935 cities and towns. Urban land management system is the most time consuming due to its accordance various stage with different parties from citizen to local authority to state authority.

It is expected that half of the population will be settled in urban areas by 2050 . The current process of managing cities seems to be out dated. Meaning that the existing cities will continue to grow larger hap-hazardously with being able to plan and implement the vision. Rapid growth pressures and disregard for many years can and have sternly strained the state of India's cities and towns. This is apparent in the numerous challenges facing them-large areas not serviced by roads, inadequate health and education, lack of sewerage water lines, slums, poor building stock, storm water networks, amenities, traffic congestion, ineffective and inadequate public transportation systems, chaotic growth and unregulated settlements, etc

Liveable, efficient, and socially and environmentally sustainable. Only then will the rapid pace of economic growth that India is undergoing be sustained and the targets of public desire of the world can be achieved. 


\subsection{Development Planning In India:}

The 74th CAA demands devolution of planning function to local authorities and involvement of people in the planning decision making process; and administratively and professionally it is expected that the system should provide for a long-term policy plan, a mid-term comprehensive plan which is further integrated with budgetary process and divided into projects/schemes for implementation, monitoring and review. In short, Development Plan is a design for the physical, social, economic and political frame work for the city, which greatly improves the quality of Urban Governance.

\subsection{Development planning Process:}

The DP is a macro strategic plan document that defines the direction of growth and envisions the citywide infrastructure for the entire development area. As per the Gujarat Town planning and urban development Act,1976 development planning process will be succeeded through Micro planning of area. For micro planning Town planning schemes is the best tool for land pooling or land readjustment. It is a comprehensive document that looks at all components of development and makes specific proposals with respect to each. In short, Development Plan is a design for the physical, social, economic and political frame work for the city, which greatly improves the quality of Urban Governance

These include the following:

- Land development-land use zoning,

- Road network and transportation

- Water supply, Sewerage, Storm water drainage

- Open spaces, green areas, Environment and pollution control

- Reclamation of areas

The DP is revised every 10 years. The process also includes limited public participation. After a draft DP is prepared by the Development Authority it is published and kept open for public inspection for a period of two months and objections and suggestions are invited. Each objection and suggestion is responded to and, if required, the DP is modified. It is published again to invite further objections and suggestions. These are again taken into account and the DP is modified. It is then sent to the State Government of Gujarat for approval and oversight. The State Government may suggest modifications, if required, before approving the DP.

\section{RESEARCH OBJECTIVE}

The objective of this research is to How Geospatial Technology can be used to develop a Development plan for the City.

1. Understand the City Components and importance of planning as a function that balance the needs of people, conflicting systems and efficient public systems.

2. Understand the Urban Development Control Regulations Rules for Development Plan.

3. Experimenting all rules and Regulation on spatial data.

\section{STUDY AREA}

Ahmedabad was known as Karnavati. In colloquial Gujarati, it is commonly called Amdavad. Archaeological evidence suggests that the area around Ahmedabad has been inhabited since 11th century, when it was known as Ashapalli or Ashaval. The city was founded in 1411 as a walled city to serve as the capital of the Sultanate of Gujarat, by Sultan Ahmed Shah, after whom the city was called Ahmedabad.

In 1487, Mahmud Begada, the grandson of Ahmed Shah fortified the city with an outer wall, $10 \mathrm{~km}$ in circumference consisting of twelve gates, 189 bastions over 6000 battlements. During the Mughal reign, Ahmedabad became one of the Thriving Centres of Trade, Mainly In Textiles, Which Were Exported To Even Europe. A Famine In 1630 And The Constant Conflicts Between The Peshwa And The Gaekwad Armies Virtually destroyed many parts of the city, causing its population to flee. Then it was ruled by the Solankis, Vaghelas, the Muzaffarid, the Mughal dynasty and the Sultanate of Delhi.

The British East Indian Company captured the city in 1818. A military cantonment was established in 1824 and a municipality in 1858. In 1864, a railway link between Ahmedabad and Bombay was established as a link for trade between northern and southern parts of India.

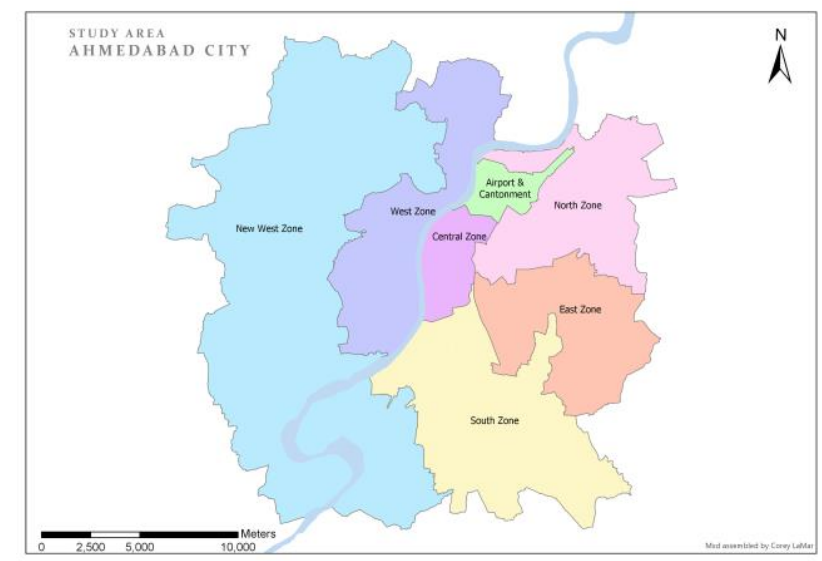

Figure 1 Study Area

Ahmedabad city is located between $72^{0} 32^{\prime} 06^{\prime \prime} \mathrm{E}-72^{\circ} 35^{\prime} 14^{\prime \prime} \mathrm{E}$ longitude $22^{0} 59^{\prime} 01$ " $\mathrm{N}-23^{0} 05^{\prime} 45^{\prime}$ " $\mathrm{N}$ latitude. The average elevation is 53 meters. It is located on the banks of River Sabarmati. The city was the capital of Gujarat after the bifurcation of the State of Bombay on 1 May 1960. In 1970, the capital was shifted to Gandhinagar. Ahmedabad is the largest city in the State of Gujarat and the seventh largest urban agglomeration in India.

\section{PROCESS OF THE DEVELOPMENT PLAN}

Urban Development Authority is making a DP: Development Plan of city, in which necessities and challenges won't be the same if compared it to past. The emerging urban challenges rapid urbanisation, poverty, informality, affordable housing, open spaces, need special attention with inputs of local knowledge of people getting affected to it in the upcoming Development Plan. One major effect of rapid development and city growth is the increase in urban land prices and developerled projects, purely based for money making rather than public happiness. Moreover the issues like public participation, 
Awareness, Lack of access to information, weak administrations, need to be shorted and process has to be made easy and faster before moving forward. These points are challenges for city and need to be taken attention while preparing the forthcoming plan of Ahmedabad with keeping in mind that is should not become a restraint for the development.

Urban planning in Ahmedabad is a two-tier process.

1. "Development Plan" (DP) is macro level plan prepared for the whole city or delineated development area.

2. "Town Planning Schemes" (TPSs) is prepared for smaller parts of the development area at micro level for which the Development Plan is prepared. Where the land pooling mechanism is utilized for land management where the local authority acts as facilitators.

This is at macro level city wide planning document. This macro strategic plan document that not only defines the direction of growth but also envisions the citywide infrastructure for the entire delineated area for further development. It is a comprehensive document which looks at each and every possible components of development and makes specific plans and schemes with respect to each other. These include the following:

- Zoning and Land development, areas to be opened up for new growth, development control regulations (which determine the built form), and allocation for public uses. (Thesis will be focused how to make this this particular components more handy and participatory).

- Transportation and Road network.

- Water supply, Sewerage and Storm water drainage

- Recreation, Open spaces, green areas

- Environment and pollution control

- Reclaimed areas

The process also comprises very limited public Engagement when $\mathrm{s}$ draft DP is prepared by the Urban Development Authority it is published and retained open for public review for a time about two months and doubts and recommendations are invited. The DP is reviewed every ten years and is modified (updated) in the provisional at whatever time a need arises to react to the changing context. Each opposition and proposal is answered to and, if essential, the DP is revised. Further objections and suggestions are taken into account after it is published again. These are again reviewed and questioned then the DP is revised.

\subsection{What is Zoning}

Almost all developed cities have regulation (rule-book) about what you can build where. They are called zoning law or development control regulations. It can also be defined as how the City is plainly break up its land into different parcel of different zones that allows different kind of activities and uses. Each of these zones give guidelines for different sizes and volumes of building block, in some cases, shapes of block. So zoning has two essential components. The first one determines where each type of land use like commercial, residential, mixed, or manufacturing can go, what can go along each other and what ought to be separated. And the second regulates what the overall shape and size of buildings can be.

\subsection{Why is Zoning Important}

Land use zoning May not be only way to make sure that people don't make ill and irrational decisions about where to locate certain type of businesses or sometimes even residences. However, it's been the standard reflective mechanism in the most cities looks like cities are staying with it. The motives that planned land use guidance is found important can include preserving property values that might decline if someone pops an detrimental business down in the middle of a pro residential neighbourhood.

The regulation of matters such as setbacks (meaning the number of feet from a street or an adjoining property line that must be maintained free of structures) helps with a solid urban design. Two homes inappropriately close together in a neighbourhood where there is some real room to roam around each house would tend to detract from the neighbourhood and therefore property values. 1

Given the major amount of effort that goes into establishing zoning regulations and a zoning map in the first place, and then into debating small changes to the regulations and map changes either initiated by the property owner or the government, the real question is about how society react to zoning. Because even where zoning is in place, zoning decisions aren't made in a vacuum there are motives behind it which may or may not be known to us. Politics can influence the decisions, in the sense that. designated officials may be troubled to go against popular request. Especially in smaller towns, popularity of the person smearing for the zoning alteration often influences whether it is approved. So to give equal rights it is necessary that whole proses is transparent with and between the public.

Sometimes the rezoning is unsuitable when it is subjective by such outside factors. Even if that is not an issue, sometimes the zoning ordinance (law) itself isn't very well shaped, or that circumstances where society have changed and the regulation didn't modify with the time. Then zoning can have unintended consequences and can actually prevent economic development of the city, some regulation which intent for flexible provisions for affordable housing, and other things that are good for your community. So what are the alternatives so that zoning can be participatory. So: zoning is important only for those who want the tried-and-true system of conserving property values through little bit update in process that supports current era and encouraging appropriate neighbouring uses. Its is need for greater flexibility and should look at more participatory approach. In rural cases where common shared values are strong, zoning often is of no importance ${ }^{8 .}$

\subsection{Illustrations and Tables}

The study has to be develop a model to obtain buildable area based on the Development rule with the help of Geospatial Technology which can be reciprocated easily to other regions as well as another scenario and analysing various such variation in different situation 


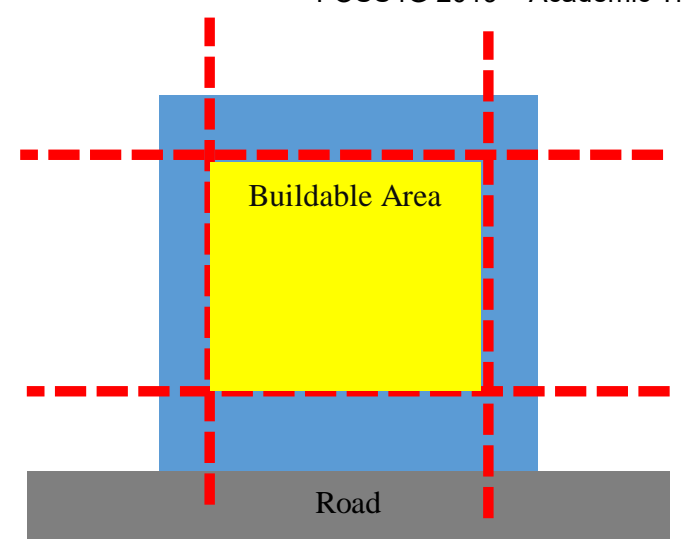

Yellow indicates Built able area.

The Development Rules can be taken into consideration of the various Rule sets and various Laws to be taken care.

Development in a plot is regulated by set of clauses of Development control regulations which are interdependent on each other. To consider all the parameters simultaneously at a time is a complex exercise.

- Road width are uniform (i.e., not varying)

- Plots are going to utilize maximum ground coverage.

- Plots start immediately after the Road (i.e., not observed particularly where TP is not implemented completely)

- Area lying under TOD

- Residential Built up is considered

\begin{tabular}{|l|l|}
\hline Road Width & Road Side Margin \\
\hline Upto $9 \mathrm{~m}$ & $2.5 \mathrm{~m}$ \\
\hline $9 \mathrm{~m}$ to $15 \mathrm{~m}$ & $3 \mathrm{~m}$ \\
\hline $15 \mathrm{~m}$ to $18 \mathrm{~m}$ & $4.5 \mathrm{~m}$ \\
\hline $18 \mathrm{~m}$ to $30 \mathrm{~m}$ & $6 \mathrm{~m}$ \\
\hline $30 \mathrm{~m}$ to $36 \mathrm{~m}$ & $7.5 \mathrm{~m}$ \\
\hline $36 \mathrm{~m}$ and above & $9 \mathrm{~m}$ \\
\hline
\end{tabular}

\begin{tabular}{|c|c|c|}
\hline Area of Plot & Rear Margin & Side Margin \\
\hline Upto $150 \mathrm{~m}^{2}$ & $2.25 \mathrm{~m}$ & - \\
\hline $150 \mathrm{~m}^{2}$ to $300 \mathrm{~m}^{2}$ & $2.25 \mathrm{~m}$ & $1.5 \mathrm{~m}$ \\
\hline $300 \mathrm{~m}^{2}$ to $500 \mathrm{~m}^{2}$ & $2.25 \mathrm{~m}$ & $3 \mathrm{~m}$ \\
\hline $500 \mathrm{~m}^{2}$ and above & $3 \mathrm{~m}$ & $3 \mathrm{~m}$ \\
\hline
\end{tabular}

Based on the literature Review comprises of Land Pooling Scheme implementation in Gujarat, Factors considered while computing FSI for a particular region, Factors influencing development on barren land as well as green field land and majorly on development control regulation (i.e., Given by AUDA) as well as Comprehensive Development Control Regulation given by Town planning and Valuation Department, Gujarat.

The Key observations are as follows

- $\quad$ Plot needs to leave more land in aspects of Frontage when a wider road is passing through it for a particular height.

- In case of Increasing Height, frontage as well as margin increases linearly.

- While margin depends on surrounding as well as height of construction taken for.

However, there are minimum dimensions of Frontage and Margin depending on area of construction needs to be considered.

\section{The Dynamic Relationship Between Floor Space and Activity System}

Three main elements which describe general dynamic structure of the activity system: activity allocation and land market, the dynamic relationship between activities and floor space, and the dynamic relationship between activities and transport. The purpose of a floor space demand model is to estimate the amount of floor space activities are willing to consume as a function of price. Land is a commodity subject to market transactions like any other commodity, but its supply is strongly determined by state intervention because of the supply of public utilities such as water, sewage, electricity, etc., and because of regulations. So, land availability will be considered as an exogenous variable to this model. One of the first models of the distribution of a given increment of floor space is due to Hansen (1959). Later Echenique, Crowther and Lindsay (1969) proposed a similar model and incorporated it into the Lowry structure to restrict resident location.

\section{RESULTS}

With the Geospatial technology identification of the net buitable area can be calculated based on the for the Development of the Rule and identify the Floor space and no of floors.

Incorporating GIS tool to determine Built able area which will be used to replicate to a larger scale, currently not being considered all the Rule of the Development Plan. Which is based on the Land use type, Type of the Road with respective widths. The deduction is made finalise the Buitable area.

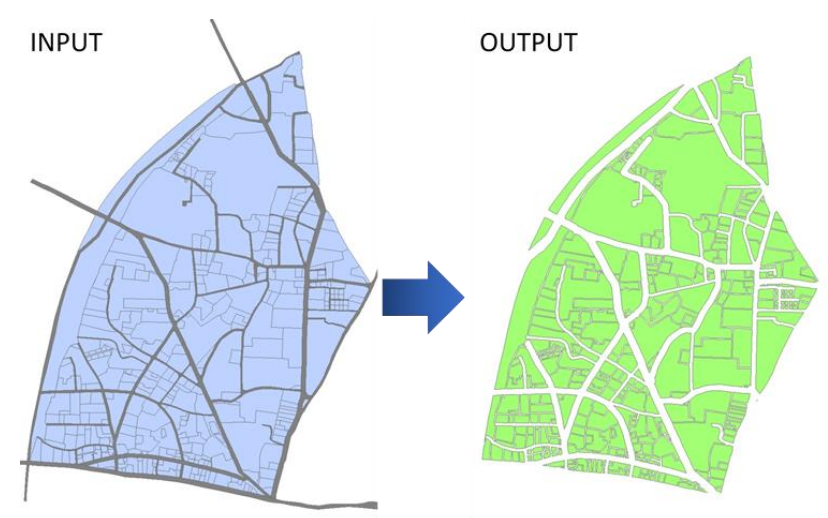

${ }^{8}$ Urban Omnibus “what-is-zoning” www.urbanomnibus.net/2014/02/what-is-zoning 


\section{CONCLUTION AND FUTURE SCOPE}

Based on the All Development rules found that the all developments are rule are not applicable in ground as the nearby road size and land use type. If the geospatial technology is used to develop a Development plan for the cities it will be very helpful to

- Identify the buildable area of a plot, the total built-up area in a city can be calculated based on the FSI provided in various zones

- This helps in providing sufficient infrastructure for the future

- It also gives an estimate on how much land needs to be opened up in future to accommodate the future population

\section{ACKNOWLEDGEMENTS (OPTIONAL)}

Acknowledgements to Mr. Aman Dodhiya \& Mr. Jash goswami of support for the project/paper/author are welcome.

\section{REFERENCES}

Land Acquisition for Master Plan: MoUD , Comprehensive Capacity Building Programme (CCBP) 2012

3. Urban growth in developing countries: a review of current trends and a caution regarding existing forecasts: World Development, Cohen B. (2004). 